\title{
The lowest-bid all-pay-auction as a fundraising mechanism: theoretically optimal but behaviorally fragile
}

Citation for published version (APA):

Damianov, D., \& Peeters, R. J. A. P. (2012). The lowest-bid all-pay-auction as a fundraising mechanism: theoretically optimal but behaviorally fragile. METEOR, Maastricht University School of Business and Economics. METEOR Research Memorandum No. 050 https://doi.org/10.26481/umamet.2012050

Document status and date:

Published: 01/01/2012

DOI:

10.26481/umamet.2012050

Document Version:

Publisher's PDF, also known as Version of record

Please check the document version of this publication:

- A submitted manuscript is the version of the article upon submission and before peer-review. There can be important differences between the submitted version and the official published version of record.

People interested in the research are advised to contact the author for the final version of the publication, or visit the DOI to the publisher's website.

- The final author version and the galley proof are versions of the publication after peer review.

- The final published version features the final layout of the paper including the volume, issue and page numbers.

Link to publication

\footnotetext{
General rights rights.

- You may freely distribute the URL identifying the publication in the public portal. please follow below link for the End User Agreement:

www.umlib.nl/taverne-license

Take down policy

If you believe that this document breaches copyright please contact us at:

repository@maastrichtuniversity.nl

providing details and we will investigate your claim.
}

Copyright and moral rights for the publications made accessible in the public portal are retained by the authors and/or other copyright owners and it is a condition of accessing publications that users recognise and abide by the legal requirements associated with these

- Users may download and print one copy of any publication from the public portal for the purpose of private study or research.

- You may not further distribute the material or use it for any profit-making activity or commercial gain

If the publication is distributed under the terms of Article $25 \mathrm{fa}$ of the Dutch Copyright Act, indicated by the "Taverne" license above, 
Damian S. Damianov, Ronald Peeters

The lowest-bid all-pay-auction as a fund-raising mechanism: Theoretically optimal but behaviorally fragile

$\mathrm{RM} / 12 / 050$

\section{METEOR}

Maastricht University School of Business and Economics Maastricht Research School of Economics

of Technology and Organization

\section{PO. Box 616}

NL - 6200 MD Maastricht

The Netherlands 


\title{
The lowest-bid all-pay-auction as a fund-raising mechanism: Theoretically optimal but behaviorally fragile*
}

\author{
Damian S. Damianov ${ }^{\dagger} \quad$ Ronald Peeters ${ }^{\ddagger}$
}

October 12, 2012

\begin{abstract}
We study the optimal design of mechanisms for the private provision of public goods in a simple setting in which donors compete for a prize of commonly known value. The optimal mechanism in this model is the lowest-price all-pay auction - a mechanism in which the highest bidder wins but all bidders pay the lowest bid. The highest amount for the public good is generated in the unique, symmetric, mixed-strategy equilibrium of this mechanism. We derive the equilibrium distribution function in a closed form for any number of bidders. We then compare various all-pay auctions and lotteries in lieu of voluntary contributions with a battery of laboratory experiments. The performance of the optimal mechanism depends on the level of competition. The lowest-price all-pay auction dominates the remaining auction formats with three competing bidders, but is inferior to the own-pay auction and the lottery with only two bidders.
\end{abstract}

JEL Classification: D44, D64

Keywords: Lowest-price all-pay auction, fund-raising mechanisms, experiments

${ }^{*}$ We thank Barnabas Bede, Catherine Eckel, Diego Escobari, Brit Grosskopf, Ernan Haruvy, Kai Konrad, Andreas Lange, Sherry Li, Jörg Oechssler, Henrik Orzen, the audiences at the ESA 2011 conference in Chicago and the Games 2012 conference in Istanbul, the seminar participants at the University of Texas at Dallas and the University of Cologne, and the workshop participants at the Max-Planck-Institute in Munich for very helpful comments and suggestions. Special thanks go to Brit Grosskopf and the Economic Research Laboratory at Texas A\&M University for their hospitality. Financial support from the the Netherlands Organisation for Scientific Research and the Faculty Research Council at the University of Texas-Pan American is gratefully acknowledged.

${ }^{\dagger}$ Department of Economics and Finance, University of Texas-Pan American. E-mail: ddamianov@utpa.edu

${ }^{\ddagger}$ Department of Economics, Maastricht University. E-mail: r.peeters@maastrichtuniversity.nl 
"The safety net will be stretched thin in some places and eliminated entirely in others. For the functions government no longer will be able to provide, we must turn to neighbors, private charities, faith-based organizations, and other local programs. Our communities, more than ever, will be asked to step up."

- Chris Gregoire, Washington state governor, December 15, 2010

\section{Introduction}

With the steady growth of the philanthropic market and the decline of government funding for various areas of public life (e.g. arts, culture, public media, higher education, hospital services, environmental protection, etc.), the design of mechanisms for the private provision of public goods has substantially gained in importance. It is well-known that fund-raising efforts based on voluntary contributions cannot provide public goods at their socially optimal levels because they suffer from a free-rider problem. While the mechanism design literature on public goods provision suggested numerous remedies to the free-rider problem, most of the solutions rely on taxation and subsidy schemes to counterbalance free-riding incentives (Clarke, 1971; Groves, 1973; Groves and Ledyard, 1977; Walker, 1981). These schemes are typically outside the domain of private charitable organizations which can use rewards, but not punishment or coercion to ensure that individuals contribute.

In this paper, we discuss the optimal design of fund-raising mechanisms in a simple public good setting in which the organizer awards a prize of commonly known value $V$ to one of the contributors. The question of main interest is how to allocate the award and how to elicit donations so as to provide the public good at a level closest to the social optimum. Our discussion focuses on silent (sealed-bid) mechanisms in which the donors participate voluntarily.

In our model there are $n \geq 2$ donors with a budget $B$ who decide how much of it to contribute to a public good and how much to keep for private consumption. There are a total number of $N$ beneficiaries from the public good (including the donors) with a marginal per capita return $\alpha$ such that $\alpha N>1>\alpha n$. In this setting, contributions are socially desirable, yet, the joint benefit of the public good to the donors - the individuals who have a budget and can contribute - does not cover the cost of public good provision. This scenario is of interest for a number of reasons. First, it occurs often in practice, especially in charity fund-raising where the proceeds from the fund-raising event goes to the benefit of others. Second, it is relevant from a theoretical standpoint because the free-riding problem cannot be resolved with trivial mechanisms. ${ }^{1}$ In our setting, mechanisms that produce the efficient outcome do not exist when budgets are sufficiently large. Therefore, we are concerned with mechanisms that

\footnotetext{
${ }^{1}$ For $\alpha n>1$ there are simple mechanisms that implement the first-best outcome even without a prize. Asking all bidders to donate their entire budget $B$, and threatening not to provide the public good otherwise implements the first-best in a Nash equilibrium. Using the "lowest common denominator" is another way to implement the first-best outcome without a prize (see Orzen, 2008).
} 
generate contributions closest to the socially optimal level. Finally, the optimal mechanism we derive has intriguing game-theoretical features, and it is natural to wonder how it performs in the laboratory relative to more commonly used formats.

Our main theoretical finding is that the lowest-price all-pay auction - in which the highest bidder wins the prize but all bidders pay the lowest bid - is optimal. It generates the highest expected revenue among all mechanisms in which donors participate voluntarily. When the budgets are sufficiently large, this expected revenue equals $\frac{V}{1-\alpha n}$ and is attained when bidders play symmetric strategies. We show that the symmetric equilibrium, given in mixed strategies, is unique, and we characterize the equilibrium cumulative distribution function in a closed form for any number of bidders. ${ }^{2}$

We test the validity of this new theoretical prediction with a series of laboratory experiments in which we compare the performance of this mechanism to various other mechanisms. We construct a total of six different mechanisms by combining two payment rules with three prize allocation rules. The payment rules consist of the pay-your-own-bid and pay-the-lowestbid formats. The allocation rules include an auction, a lottery and a random assignment of the prize regardless of contribution amounts (i.e. Tullock contests with contest parameters $\infty, 1$ and 0$)$.

We report several notable differences between theoretical predictions and laboratory behavior. Probably the most important finding is that the relative performance of the lowest-bid all-pay auction critically depends on the number of donors. Among the six mechanisms, the theoretically optimal format generates disappointing revenue in the lab with two donors, but is the superior mechanism with three donors.

The design features of the lowest-bid auction format generate two effects that lead to a high level of contributions in the theoretical equilibrium of this mechanism. The one effect is the shilling effect experienced by the lowest bidder: by increasing his bid, the lowest bidder raises the contributions of all participants. The other effect is the free-riding effect experienced by the other bidders: raising a bid improves the chance of winning the prize but does not increase the contribution level of a bidder. For a given symmetric mixed strategy profile, both effects reduce the cost of raising one's bid in the current scenario where contributions are used to finance a public good. ${ }^{3}$

We note, however, that the symmetric mixed strategy solution relies on the assumption that, when submitting high bids, bidders take into account that their contribution will most likely be much lower because it is determined by the lowest order statistics. Our experimental results suggest that subjects develop a confidence that they will be paying significantly less

\footnotetext{
${ }^{2}$ This mechanism, however, supports asymmetric equilibria in which at least one of the participants does not donate and total contributions equal zero. The existence of these zero-contribution equilibria is not tied to the particular complete information setting considered here. These equilibria, which are similar to the zero-bid equilibria in the second-price auction (see e.g. Blume and Heidhues, 2004), also exist in incomplete information private and common value settings.

${ }^{3}$ These arguments have been recently proposed by Jeff Carpenter to explain why in theory the lowest-bid format produces higher revenue than the pay-your-bid format.
} 
than their bids and bid more aggressively only if there is a sufficient number of actively participating bidders.

The results we present here can be used for several purposes. First, our model helps establish the theoretical limits to fund-raising through private contributions. Exploring these limits can help make better policy predictions (see e.g. Andreoni, 1998). As tax revenues decline, budget deficits grow, and cuts in social programs are being discussed, such findings can help policy-makers better assess to what extent communities can continue to provide public goods without raising taxes. Second, our experimental study compares novel fundraising formats alongside the more widely used ones. Given the high stakes involved for fundraisers in experimenting with different formats, advice on novel fund-raising methods should probably come first from theory and the lab. Finally, our study provides insights that open interesting opportunities for future research. In particular, our results hint at the important role of participation in fund-raising events, which may be tied to the particular mechanism implemented. An important extension would be to allow for endogenous participation in the fund-raising mechanism; see Konrad (2009) and Dechenaux, Kovenock and Sheremeta (2012) for a survey of the existing literature on contests with voluntary participation.

The rest of the paper is organized as follows. In Section 2 we explain how our paper relates to the existing literature on charitable fund-raising. In Section 3 we introduce the model, and in Section 4 we derive the optimal mechanism. Section 5 contains the experimental results. Section 6 concludes with a summary of the main findings and suggestions for future research.

\section{Related literature}

The analysis of prize-based mechanisms for public goods provision has been an active and fast-evolving area of research in the last decade. Morgan (2000) and Morgan and Sefton (2000) present theoretical results and experimental evidence showing that lotteries generate higher revenue than the voluntary contribution mechanism. More recently, Goeree, Maasland, Onderstal and Turner (2005) show how tools from the optimal auction design literature can be used to derive mechanisms that are best at raising money for a public good. They consider the symmetric independent private value model in which bidders receive an additional benefit proportional to the revenue generated by the mechanism. In this setting, the revenue equivalence theorem does not hold. Goeree et al. (2005) show that all-pay auctions generate more revenue than winner-pay auctions. Further, auctions outperform lotteries as they allocate the prize to the donor who values the prize the most. The optimal mechanism they derived is similar in structure to the mechanism derived here: it is the lowest-price all-pay auction, yet it needs to be augmented by an appropriately chosen entry fee and a reserve price which serve the purpose of screening out low-value bidders. In the optimal mechanism of this model the seller retains the prize with a positive probability.

Our focus on a prize of commonly known value helps disentangle the theoretical reasons for 
the superiority of auctions over lotteries and gain two important additional insights. First, allpay auctions outperform lotteries not only because they allocate the prize efficiently. Auctions generate more revenue than lotteries also when the prize is of commonly known value and efficiency is not an issue. We demonstrate that this result applies both for the own-bid and the lowest-bid payment rule. Second, when the prize is of common value, the optimal mechanism entails no reserve prize and no entry fee. The optimal mechanism transfers the prize to the donors with a probability of one. The optimality of the lowest-price all-pay auction in this setting is not conditional on the seller's commitment to sell the item. It may appear at first glance that our results can be obtained as a limiting case of the independent private value model in which the distribution of bidder valuations in the limit reduces to a single point. While such a conjecture may seems intuitively appealing, it cannot be pursued with the use of equilibrium purification arguments (see e.g. Govindan, Reny and Robson, 2003; Harsanyi 1973) because the available equilibrium purification results apply to finite games only. In fact, the equilibrium distribution functions we obtain do not seem to be special cases of Goeree et al.'s (2005) Bayes-Nash equilibrium distributions when uncertainty vanishes.

Goeree et al.'s (2005) mechanism ranking has been studied also with laboratory experiments. Schram and Onderstal (2009) compare first-price winner-pay versus first-price all-pay auctions and lotteries in a setting with independent private values and show that the all-pay format generates a substantially higher revenue. Because of these findings we compare here only the better performing all-pay formats and include the theoretically superior lowest-price mechanisms in the comparison.

Two experiments have been recently conducted that focus on variations of the fixed-prize model that we consider here. Duffy and Matros (2012) analyze self-financing (or provisional) mechanisms in which the public good is provided only if total donations exceed the value of the prize; donations are refunded otherwise. Interestingly, in this setting the first-price all-pay auction has no equilibria which lead to positive donations. The major finding of this paper is that that the lottery outperforms the all-pay auction both in theory and experimentally. Orzen (2008) is probably the most closely related study to ours in that it considers the lowestprice all-pay auction alongside all-pay auctions and lotteries in an experiment. Orzen's setting, however concerns the case in which the contributors' joint benefit exceed the cost of the public good (i.e. $\alpha n>1$ ). In this setting, as we discussed earlier, simple mechanisms exist which implement the efficient allocation. For instance, donating the entire budget to the public good is a dominant strategy equilibrium of the lowest-price format even if no prize is awarded to the donors. This mechanism, which Orzen termed the "lowest common denominator" and the lowest-price all-pay auction outperform the own-bid all-pay auction and the lottery both theoretically and experimentally.

The fund-raising potential of all-pay mechanisms has also been studied in several alternative settings. Lange, List and Price (2007) focus on lotteries only but allow for risk aversion and heterogeneity in the marginal per capita return of donors. In this setting, lotteries out- 
perform the voluntary contribution mechanism, both in theory and experimentally, but the optimal mechanism can be a single or multiple-prize lottery depending on the risk posture and preference heterogeneity of contributors. Corazzini, Faravelli and Stanca (2009) conduct an experiment allowing for heterogeneity and incomplete information about individual income. In contrast to theory, in the lab individual contributions are higher in the lottery than in the all-pay auction. Bos (2011) shows how lotteries can outperform auctions also in theory in a complete information model in which agents have sufficiently different valuations for the prize and marginal per capita returns.

The fund-raising potential of all-pay mechanisms has been studied recently also in the field. In a door-to-door fund-raising experiment, Landry, Lange, List, Price and Rupp (2006), find that lotteries raise more funds than the voluntary contribution mechanism, controlling for various factors related to the solicitor. In another door-to-door experiment Onderstal, Schram and Soetevent (2011) compare the all-pay auction, the lottery and two versions of the voluntary contributions mechanism (anonymous and non-anonymous). They report that the auction generated the least revenue despite being superior in theory. Carpenter, Holmes and Matthews (2008) compare the performance of the own-bid all-pay auction and winner-pay auctions (first and second price) in a field experiment. In contrast to theory, they find that the own-bid all-pay auction is dominated by the first-price auction - a result that the authors attribute to endogenous participation, and the lack of familiarity with the all-pay format.

\section{Preliminaries}

A set $N=\{1, \ldots, n\}$ of two or more potential donors participate in a fund-raising event. All participants are risk neutral and have a budget $B$ which they divide between contribution to a public good and personal consumption. As in Goeree et al. (2005), we assume that the value of the public good for each participant is a constant fraction $\alpha$ of total funds raised for the public good. If $\alpha \geq \frac{1}{n}$, the free-rider problem can easily be resolved with simple arrangements according to which all contributors agree to donate a certain amount, and if at least one of them does not contribute, the public good is not provided (see Bagnoli and Lipman, 1989; Bagnoli and McKee, 1991; Orzen, 2008). One notable disadvantage of these mechanisms is that they do not generate donations when $\alpha<\frac{1}{n}$. This case appears to be quite relevant in the practice of fund-raising because the set of potential beneficiaries from the public good is much larger than the original set of donors. In fact, often the beneficiaries of charitable donations are outside the set of the contributors. Therefore, in this paper, as in Goeree et al. (2005), we will focus on the case $\alpha<\frac{1}{n}$, although the mechanisms we explore solve the free-riding problem also in the alternative case.

We consider the problem of a charitable organization which chooses a mechanism to award a prize of common value $V$ to one of the participating donors. We analyze a one-shot setting in which each participant $i \in N$ announces his or her willingness to contribute to the public 
good, $x_{i}$. A mechanism in our setting consists of an allocation rule $P_{i}\left(x_{i}, x_{-i}\right)$ which maps the willingness to contributes of all participants into a probability of winning the prize for each donor, and a payment rule $C_{i}\left(x_{i}, x_{-i}\right)$ which maps the agents' willingness to contribute into actual donations. If bidders participate in the mechanism with an allocation rule $P_{i}\left(x_{i}, x_{-i}\right)$ and a payment rule $C_{i}\left(x_{i}, x_{-i}\right)$, the expected payoff of bidder $i \in N$ is specified as follows:

$$
\Pi_{i}\left(x_{i}, x_{-i}\right)=\left[B-C_{i}\left(x_{i}, x_{-i}\right)\right]+\alpha \cdot \sum_{j \in N} C_{j}\left(x_{j}, x_{-j}\right)+P_{i}\left(x_{i}, x_{-i}\right) \cdot V .
$$

The first term gives the payoff from private consumption. The second term presents the benefit from the public good. The third term captures the expected benefit from winning the prize.

We focus on the set of voluntary mechanisms, that is, mechanisms in which agents cannot be asked to contribute more than their expressed desire to contribute $\left(C_{i}\left(x_{i}, x_{-i}\right) \leq x_{i}\right)$ and in which the utility from participation in equilibrium is not below the utility from nonparticipation or donating zero $\left(\Pi_{i}\left(x_{i}, x_{-i}\right) \geq \Pi_{i}\left(0, x_{-i}\right)\right)$. In our experiments, we focus on three versions of $P_{i}$ and two versions of $C_{i}$ :

$$
P_{i}(x)= \begin{cases}\frac{1}{n} & (\mathrm{VCM}) \\ \frac{1}{\operatorname{argmax}_{j \in N} x_{j} \mid} \cdot \mathbb{1}_{\left[i \in \operatorname{argmax}_{j \in N} x_{j}\right]} & \text { (AUCtion) } \\ \sum_{j \in N} x_{j} & \text { (LOTtery) }\end{cases}
$$

and

$$
C_{i}(x)= \begin{cases}x_{i} & (\text { OWN bid }) \\ \min _{j \in N} x_{j} & (\text { LOWest bid })\end{cases}
$$

To facilitate the analysis, in the following statement we present a strategic equivalence argument which allows us to analyze the current mechanisms as alternative games without a public good element.

Lemma 1. Mechanisms with own-bid payment rule in an environment with a public good element are strategically equivalent to mechanisms in an environment without a public good element (i.e. $\alpha=0$ ) in which a prize of the amount $\frac{V}{1-\alpha}$ is awarded. Mechanisms with lowestbid payment rule in an environment with a public good element are strategically equivalent to mechanisms in an environment without a public good element in which a prize of the amount $\frac{V}{1-\alpha n}$ is awarded.

Proof. In the own-bid mechanisms with a public good element the payoff equals

$$
\begin{aligned}
\Pi_{i}^{\mathrm{OWN}}(\alpha, V)\left(x_{i}, x_{-i}\right) & =B-x_{i}+\alpha \cdot \sum_{j \in N} x_{j}+P_{i}\left(x_{i}, x_{-i}\right) \cdot V \\
& =\alpha \cdot\left(B+\sum_{j \neq i} x_{j}\right)+(1-\alpha) \cdot\left(B-x_{i}+P_{i}\left(x_{i}, x_{-i}\right) \cdot \frac{V}{1-\alpha}\right) \\
& =\alpha \cdot\left(B+\sum_{j \neq i} x_{j}\right)+(1-\alpha) \cdot \Pi_{i}^{\mathrm{OWN}}\left(0, \frac{V}{1-\alpha}\right)\left(x_{i}, x_{-i}\right)
\end{aligned}
$$


which is an affine transformation of the same setting without a public good element and a prize of $\frac{V}{1-\alpha}$. In the lowest-bid mechanisms with public good element the payoff equals

$$
\begin{aligned}
\Pi_{i}^{\mathrm{LOW}}(\alpha, V)\left(x_{i}, x_{-i}\right) & =B-\min _{j \in N} x_{j}+\alpha n \cdot \min _{j \in N} x_{j}+P_{i}\left(x_{i}, x_{-i}\right) \cdot V \\
& =\alpha n \cdot B+(1-\alpha n) \cdot\left(B-\min _{j \in N} x_{j}+P_{i}\left(x_{i}, x_{-i}\right) \cdot \frac{V}{1-\alpha n}\right) \\
& =\alpha n \cdot B+(1-\alpha n) \cdot \Pi_{i}^{\mathrm{LOW}}\left(0, \frac{V}{1-\alpha n}\right)\left(x_{i}, x_{-i}\right)
\end{aligned}
$$

which is an affine transformation of the setting without public good element and a prize of $\frac{V}{1-\alpha n}$.

In the public good setting we study, for each dollar donated, each player receives a fraction of $\alpha$ back in the form of benefits from the public good. Thus, donating a dollar in our public good setting is equivalent to donating only $1-\alpha$ in the own-bid mechanisms and $1-\alpha n$ in the lowest-bid mechanisms in a setting without a public good. As the above arguments show, with an appropriate scaling of the prizes we can generate games without a public good which are strategically equivalent to the public good games we study.

\section{Optimal design}

In this section we show that the lowest-bid all-pay auction is the optimal design. We first state some properties of symmetric mixed strategy equilibria and show that the expected payoff in a symmetric equilibrium is $\frac{V}{1-\alpha n}$. Next, we derive the cumulative distribution function of bids in a symmetric equilibrium and demonstrate that this symmetric equilibrium is unique. Then we demonstrate that a higher payoff cannot be generated by any voluntary participation mechanism. Finally, we show that asymmetric equilibria exist in the lowest-bid all-pay auction mechanism when the budget constraint is sufficiently high.

Proposition 1 (Symmetric equilibrium in mixed strategies).

(a) No budget constraint. There is a unique symmetric equilibrium in mixed strategies with a cumulative distribution function given by the following differential equation

$$
F^{\prime}(x)=\frac{1-\alpha n}{V} \cdot \frac{(1-F(x))^{n-1}}{(n-1) F^{n-2}(x)}
$$

with an initial condition $F(0)=0$.

(b) High budget constraint: $B \geq \frac{V}{n(1-\alpha n)}$. There is a unique symmetric equilibrium in which bidders randomize on the interval $[0, b]$ according to $F(x)$ and donate their entire budget with a probability of $1-F(b)$. The cutoff value $b$ is determined by the unique solution to the equation

$$
\frac{V}{1-\alpha n} \cdot\left[\frac{1-F(b)^{n}}{n(1-F(b))}-F(b)^{n-1}\right]=[1-F(b)]^{n-1}(B-b) .
$$


(c) Low budget constraint: $B<\frac{V}{n(1-\alpha n)}$. In the unique equilibrium bidders contribute their entire budgets.

Proof. Using Lemma 1, we focus on the environment without a public good. It is easy to see that no symmetric equilibrium in pure strategies exists because each bidder has an incentive to increase his bid and secure the prize without paying more. Thus, we consider the mixed strategy extension of the game in which each player $i \in N$ chooses a cumulative distribution function $F_{i}(x)$ over the set of pure strategies. Let us also denote by $\phi_{i}(\tilde{x})=F_{i}(\tilde{x})-\lim _{x \uparrow \tilde{x}} F_{i}(x)$ the size of a mass point placed at bid $\tilde{x}$. We proceed now in several steps.

Step 1. There are no mass points in the symmetric equilibrium distribution (except at the budget constraint $B$ ). Assume that there exists an atom in the symmetric equilibrium distribution, i.e. there is a mass point at bid $\tilde{x}$. With a probability of $\phi_{i}^{n-1}(\tilde{x})$ there is a tie at this bid in which case bidder $i$ wins the prize only with a probability of $1 / n$. Consider a deviation according to which bidder $i$ shifts the mass $\phi_{i}(\tilde{x})$ from $\tilde{x}$ to $\tilde{x}+\epsilon$. The total probability of winning the prize will increase by at least $\left(1-\frac{1}{n}\right) \cdot \phi_{i}^{n-1}(\tilde{x})$, while the payment will increase by no more than $\epsilon$ (observe that the payment function is continuous). For a small enough $\epsilon$ the deviation is profitable.

Step 2. The lower bound of the support of the symmetric equilibrium is zero. Assume on the contrary that the lower bound is $\ell>0$. Because the distribution is atom-less, with a bid of $\ell$, bidder $i$ pays $\ell$, but the chance of winning the prize is zero. So, a bid of zero is a profitable deviation.

Step 3. In the symmetric equilibrium each bidder contributes on average the amount $\frac{V}{n(1-\alpha n)}$. As the bid of zero is in the support of the mixed strategy equilibrium, and the payoff is $B$ when this bid is played, the expected payoff of each bidder in a symmetric equilibrium must be $B$. Let $E$ be the expected payment of each bidder (assuming symmetric equilibrium strategies). The expected payoff of the equilibrium mixed strategy equals the expected payoff of each strategy in the support, in particular the bid of zero. Observe now that with a bid of zero the chance of a bidder to win the prize is zero, and total contributions equal zero as well. Thus, if according to the symmetric equilibrium distribution function each bidder donates on average $E$, the following equation holds for $E$

$$
\frac{V}{n}+\alpha \cdot n \cdot E-E=0 \quad \Longleftrightarrow \quad E=\frac{V}{n(1-\alpha n)} .
$$

Step 4. Derivation of equilibrium mixed strategies. We consider the case without a budget constraint first. The equilibrium distribution function is atom-less and the expected payoff in a symmetric equilibrium is zero with each bid $x$. Hence, if we assume that the equilibrium distribution function is continuously differentiable, then it must satisfy the equation

$$
F^{n-1}(x) \cdot \frac{V}{1-\alpha n}-\int_{0}^{x} y d\left[1-(1-F(y))^{n-1}\right]-(1-F(x))^{n-1} \cdot x=0 .
$$

The first term is the expected gain from winning the prize. The second term is the expected payment when at least one of the bidders bids below $x$. This is the lowest order statistic of all 
other bidders, conditional on this lowest order statistic being below $x$. The third term is the probability that all other bidders bid above $x$, multiplied by the payment $x$. The derivative of the left hand-side equals:

$$
\begin{aligned}
& (n-1) F^{n-2}(x) F^{\prime}(x) \cdot \frac{V}{1-\alpha n}-x \cdot \frac{d}{d x}\left[1-(1-F(x))^{n-1}\right] \\
& \quad-(1-F(x))^{n-1}+(n-1)(1-F(x))^{n-2} F^{\prime}(x) \cdot x \\
& =(n-1) F^{n-2}(x) F^{\prime}(x) \cdot \frac{V}{1-\alpha n}-x \cdot(n-1)(1-F(x))^{n-2} F^{\prime}(x) \\
& \quad-(1-F(x))^{n-1}+(n-1)(1-F(x))^{n-2} F^{\prime}(x) \cdot x \\
& =(n-1) F^{n-2}(x) F^{\prime}(x) \cdot \frac{V}{1-\alpha n}-(1-F(x))^{n-1} .
\end{aligned}
$$

Equating this expression to zero and rearranging terms, we obtain that the equilibrium distribution function satisfies the differential equation

$$
F^{\prime}(x)=\frac{1-\alpha n}{V} \cdot \frac{(1-F(x))^{n-1}}{(n-1) F^{n-2}(x)}
$$

with an initial condition $F(0)=0$.

Step 5. The symmetric equilibrium is unique. So far we derived one symmetric equilibrium. We will demonstrate here that this equilibrium is unique. We proceed by contradiction. Assume that there are two symmetric equilibria, given by the cumulative distribution functions $F(x)$ and $G(x)$. Using the standard definition of stochastic dominance, we say that $F(x)$ first degree stochastically dominates $G(x)$ if $F(x) \leq G(x)$ for all $x$ with strict inequality for some $x$. Since both distributions are assumed to be equilibria, then it cannot be the case that $F(x)$ dominates $G(x)$ of first degree (or vice versa). Indeed, if this were the case, then the lowest order statistic of $F(x)$, given by the distribution $1-(1-F(x))^{n}$ would stochastically dominate the lowest order statistic of $G(x)$, given by $1-(1-G(x))^{n}$. As expected revenue is $n$ times the expected value of the lowest order statistic, it is clear that both distributions will lead to different expected revenues. This contradicts the result we established that the expected contributions in every mixed strategy equilibrium equal $\frac{V}{1-\alpha n}$ (see Step 3). As both functions, being equilibrium distributions, are continuous, and $F(0)=G(0)=0$, the two must cross at least one more time. Let us assume that $y>0$ is the minimum point at which they cross again, i.e. $F(y)=G(y)$, and without loss of generality let us assume that $F(x) \leq G(x)$ for $0 \leq x \leq y$. Then, in the interval $[0, y]$, on average, one of the distributions will result in a higher payment for the bidders than the other. This is, however, not possible, because the expected payoff is zero at all points in the support, and at both points the probability of winning the item is the same. That is, the same increase in probability should be gained by the same increase in the expected payment. Thus, there is only one symmetric mixed strategy equilibrium.

Step 6. Equilibrium derivation with budget constraint B. To show that the strategy profile described in the proposition is indeed an equilibrium, we need to show that all bids that 
belong to the support yield the same expected revenue (of zero) for a bidder, given that the other bidders follow the described equilibrium strategy. Observe that all bids in $[0, b]$ generate the same probability of earning the prize as in the case with no budget constraint, and the expected payments with these bids are also the same. We will now show that the bid $B$ generates the same payoff as the bid $b$. Note that the only case in which a bid $B$ will win the item and a bid $b$ will not is when there is at least one other bidder who bids $B$. If several bidders bid $B$ there will be a tie. Let bidder $i$ submit a bid of $B$. The additional probability for this bidder to win the item (compared to the situation in which he bids $b$ ) is given by the following binomial expression describing the probabilities of a tie for bidder $i$ and any number of his rivals from 1 to $(n-1)$ :

$$
\sum_{j=1}^{n-1}\left(\begin{array}{c}
n-1 \\
j
\end{array}\right)(1-F(b))^{j} F(b)^{n-1-j} \frac{1}{j+1} .
$$

A standard manipulation of the above expression yields

$$
\frac{1-F(b)^{n}}{n(1-F(b))}-F(b)^{n-1}
$$

Thus, the additional expected gain from bidding $B$ instead of $b$ is

$$
\frac{V}{1-\alpha n} \cdot\left[\frac{1-F(b)^{n}}{n(1-F(b))}-F(b)^{n-1}\right] .
$$

With a bid of $B$ bidder $i$ pays the same as with the bid $b$ when at least one of his rivals bids below $B$. When all other bidders bid $B$, then bidder $i$ pays $B$. Thus, the additional cost of raising the bid from $b$ to $B$ is

$$
[1-F(b)]^{n-1}(B-b) .
$$

The condition given in the proposition equates the expressions (2) and (3) and ensures that the benefit of raising the bid from $b$ to $B$ corresponds to the cost. To see that bids in the interval $(b, B)$ do not lead to a higher payoff for a bidder observe that the winning probability and the expected payoff with these bids are the same as with the bid $b$. The uniqueness of the symmetric equilibrium established in Step 5 guarantees that there is a unique $b$ which solves the equation given in the proposition.

The cumulative distribution function can be given in explicit form for $n=2$ bidders. In the case of $n>2$ bidders, the differential equation in (1) cannot be solved explicitly. However, the inverse of the cumulative symmetric equilibrium distribution function can be derived in a closed form. These results are summarized in the following proposition.

Proposition 2 (Symmetric equilibrium distribution). In the case $n=2$ the symmetric equilibrium takes the form

$$
F(x)=1-e^{-c \cdot x}
$$


with $c=\frac{1-\alpha n}{V}$.

In the case $n>2$ the inverse of the cumulative distribution function takes the form

$$
F(y)^{-1}=\frac{(n-1)}{c} \cdot\left[\frac{1}{n-2}\left(\frac{y}{1-y}\right)^{n-2}-\frac{1}{n-3}\left(\frac{y}{1-y}\right)^{n-3}+\ldots-\frac{1}{2}\left(\frac{y}{1-y}\right)^{2}+\frac{y}{1-y}-\ln (1-y)\right]
$$

when $n$ is odd, and

$$
F(y)^{-1}=\frac{(n-1)}{c} \cdot\left[\frac{1}{n-2}\left(\frac{y}{1-y}\right)^{n-2}-\frac{1}{n-3}\left(\frac{y}{1-y}\right)^{n-3}+\ldots+\frac{1}{2}\left(\frac{y}{1-y}\right)^{2}-\frac{y}{1-y}+\ln (1-y)\right]
$$

when $n$ is even.

Proof. Equation (1) is an autonomous equation. Denoting $y=F(x)$ we can write

$$
\frac{d y}{d x}=c \cdot \frac{(1-y)^{n-1}}{(n-1) y^{n-2}}
$$

or

$$
\frac{(n-1) y^{n-2}}{c \cdot(1-y)^{n-1}} \cdot d y=d x
$$

where $c=\frac{1-\alpha n}{V}$. Integrating with $z=\frac{y}{1-y}$ we obtain

$$
x+K=\frac{(n-1)}{c} \cdot \int \frac{y^{n-2}}{(1-y)^{n-1}} d y=\frac{(n-1)}{c} \cdot \int \frac{z^{n-2}}{z+1} d z .
$$

If $n$ is odd we have

$$
\begin{aligned}
x+K & =\frac{(n-1)}{c} \cdot \int \frac{z^{n-2}+1-1}{z+1} d z \\
& =\frac{(n-1)}{c} \cdot \int\left(z^{n-3}-z^{n-4}+\ldots-z+1-\frac{1}{z+1}\right) d z \\
& =\frac{(n-1)}{c} \cdot\left[\frac{z^{n-2}}{n-2}-\frac{z^{n-3}}{n-3}+\ldots-\frac{z^{2}}{2}+z-\ln |z+1|\right] \\
& =\frac{(n-1)}{c} \cdot\left[\frac{1}{n-2}\left(\frac{y}{1-y}\right)^{n-2}-\frac{1}{n-3}\left(\frac{y}{1-y}\right)^{n-3}+\ldots-\frac{1}{2}\left(\frac{y}{1-y}\right)^{2}+\frac{y}{1-y}-\ln (1-y)\right] .
\end{aligned}
$$

If $n$ is even we have

$$
\begin{aligned}
x+K & =\frac{(n-1)}{c} \cdot \int \frac{z^{n-2}-1+1}{z+1} d z \\
& =\frac{(n-1)}{c} \cdot \int\left(z^{n-3}-z^{n-4}+\ldots+z-1+\frac{1}{z+1}\right) d z \\
& =\frac{(n-1)}{c} \cdot\left[\frac{z^{n-2}}{n-2}-\frac{z^{n-3}}{n-3}+\ldots+\frac{z^{2}}{2}-z+\ln |z+1|\right] \\
& =\frac{(n-1)}{c} \cdot\left[\frac{1}{n-2}\left(\frac{y}{1-y}\right)^{n-2}-\frac{1}{n-3}\left(\frac{y}{1-y}\right)^{n-3}+\ldots+\frac{1}{2}\left(\frac{y}{1-y}\right)^{2}-\frac{y}{1-y}+\ln (1-y)\right] .
\end{aligned}
$$

In either case, the initial condition $y(0)=0$ gives $K=0$.

From Step 3 of the proof of Proposition 1 we derive the following result. 
Proposition 3 (Expected revenue). When $B \geq \frac{V}{n(1-\alpha n)}$, in the unique symmetric equilibrium, expected total donations equal $\frac{V}{1-\alpha n}$. When $B<\frac{V}{n(1-\alpha n)}$, donations aggregate to $n B$ in equilibrium.

Our next result establishes the optimality of the lowest-price all-pay auction. In fact, this mechanism is optimal among a slightly larger set of mechanisms, including awarding multiple prizes of total value $V$ and all possible ways in which the winner of each prize is determined.

Proposition 4 (Optimal mechanisms). Among all mechanisms which transfer a total value $V$ to the bidders, and all bidders participate voluntarily (i.e. bidders in equilibrium do not earn less compared to the case in which they don't donate), the lowest-price all-pay auction generates the highest expected revenue of $\frac{V}{1-\alpha n}$.

Proof. Let us denote by $\varphi_{i}=\varphi_{i}\left(F_{i}^{*}\left(x_{i}\right), F_{-i}^{*}\left(x_{-i}\right)\right)$ the transfer that a voluntary mechanism prescribes to bidder $i \in N$ when bidders play a symmetric mixed strategy Nash equilibrium. ${ }^{4}$ Similarly, we denote by $C_{i}=C_{i}\left(F_{i}^{*}\left(x_{i}\right), F_{-i}^{*}\left(x_{-i}\right)\right)$ the expected contribution of bidder $i$ in a symmetric equilibrium. We now establish an upper bound on the total revenue generated by any mechanism using the voluntary participation constraint. For each $i \in N$ this constraint is given by $\varphi_{i}+\alpha \cdot \sum_{j \in N} C_{j} \geq C_{i}$. Summing over all $i$ we obtain

$$
\sum_{i \in N} \varphi_{i}+\alpha n \cdot \sum_{j \in N} C_{j} \geq \sum_{i \in N} C_{i} \Longleftrightarrow V+\alpha n \cdot \sum_{j \in N} C_{j} \geq \sum_{j \in N} C_{j} \Longleftrightarrow \sum_{j \in N} C_{j} \leq \frac{V}{1-\alpha n} .
$$

Thus, due to the participation constraint, no higher revenue can be generated by any voluntary mechanism.

We next turn to the discussion of asymmetric equilibria leading to zero expected payoff in the lowest-price all-pay auction.

Proposition 5 (Asymmetric equilibria). When $B \geq \frac{V}{n(1-\alpha n)}$ asymmetric equilibria exist. In every asymmetric equilibrium a zero contribution belongs to the support of at least one bidder, and the expected payoff of this bidder is zero. There are asymmetric equilibria in which at least one of the bidders does not contribute (with a probability of one) and the total amount of donations is zero in this equilibrium.

Proof. Assume by way of contradiction that zero is not in the support of any bidder. We will argue that all bidders have the same lower bound of their support in all equilibria. Indeed, assume not, and take the bidder with the smallest lower bound of the support. Assume that this is bidder $i$ and the support is $\ell_{i}>0$. Let the next lowest bound of the mixed strategy support be $\ell_{j}$, the lower bound for bidder $j$. Let $\phi_{i}\left(\left[\ell_{i}, \ell_{j}\right)\right)$ be the mass that bidder $i$ places on the interval $\left[\ell_{i}, \ell_{j}\right)$. As these bids never win (they always lose against bidder $j$ ), but require

\footnotetext{
${ }^{4}$ For the set of mechanisms in which a single prize is awarded, this transfer is $\varphi_{i}\left(F_{i}^{*}\left(x_{i}\right), F_{-i}^{*}\left(x_{-i}\right)\right)=$ $P_{i}\left(F_{i}^{*}\left(x_{i}\right), F_{-i}^{*}\left(x_{-i}\right)\right) \cdot V$.
} 
bidder $i$ to pay a positive amount, it will be a profitable deviation for bidder $i$ to transfer the mass $\phi_{i}\left(\left[\ell_{i}, \ell_{j}\right)\right)$ to zero. Hence, we conclude that all bidders must have the same lower bound. Using arguments we established earlier regarding the symmetric equilibrium (see Step 1 of the proof of Proposition 1) we conclude that there is no mass point at the lower bound of the support of the mixed strategy equilibrium. Hence, by playing $\ell_{i}>0$ a bidder will not win with a probability of one, but has to pay a positive amount. So, bidding zero will be a profitable deviation - a contradiction to the assumption that zero is not in the support of any bidder. It is easy to see that there are asymmetric equilibria in which all bidders bid $B$ except for one who bids 0 . This equilibrium play leads to zero total revenue.

The analytical techniques developed here for the lowest-bid all-pay auction can be applied to also characterize the equilibria in the own-bid all-pay auction with a budget constraint. An equilibrium analysis of the own-bid auction format is provided in Appendix B.

\section{The experiment}

\subsection{Design, procedures and theoretical predictions}

We conducted an experiment to test the theoretical optimality of the lowest-bid all-pay auction. In the experiment, we compared the performance of six different mechanisms that are obtained by combining two variations of the payment rule (own-bid and lowest-bid) with three variations of the allocation rule (VCM, lottery, and auction). In order to explore the role of competition in the functioning of these mechanisms, we added the number of active agents (i.e. agents who have a budget and can contribute to the public good) as another treatment variation. In total our experiment consisted of twelve treatments (two for each mechanism).

For each treatment, an experimental session was conducted with different subjects. Students from Texas A\&M University and the University of Texas-Pan American were recruited to participate in an experiment in economic decision-making in which money can be earned. It was made clear that they would be paid in cash at the end of the session and that sessions take approximately 75 minutes.

In each session there were 20 subjects participating. Subjects were seated behind isolated computer terminals, via which the experiment was run. After subjects read the instructions, answered the control questions correctly, and eventual clarifying questions were answered, the z-Tree software (Fischbacher, 2007) was started. ${ }^{5}$

Each session consisted of 20 rounds. At the beginning of each round, subjects were randomly assigned to groups of four. Subjects were not aware of whom they were grouped with, but they did know that the group composition changed every round. Depending on the treatment, either two or three randomly chosen subjects in each quadruple were assigned the role of active agent while the remaining agent(s) were assigned the role of passive agent.

\footnotetext{
${ }^{5}$ Instructions are available upon request.
} 
The active agents had a budget of 100 tokens, and they had to specify how much of this budget they are willing to contribute (their bid) to the public good. The passive agents had no budget and benefited only from the donations of the active agents.

In the treatments with own-bid payment rule, the actual contribution for each active bidder corresponded to his/her own willingness-to-contribute, while in the treatments with lowest-bid payment rule, the actual contribution for an active agent was determined by the lowest willingness-to-contribute specified by the active agents in the group. For each active agent, the actual contribution was subtracted from the given budget. The benefit from the public good, both for active and passive agents, equaled the sum of the actual contribution multiplied by the marginal per capita return of 0.3 .

In addition to these earnings, a prize of 20 tokens was allocated to one of the active agents in a group. In the VCM the prize was randomly assigned to one of the active agents. In the lottery treatments, the probability of winning the prize was proportional to the agent's willingness-to-contribute. In the auction treatments, the prize was awarded to the agent with the highest willingness-to-contribute (ties were resolved at random).

After each round of play, subjects received information on the willingness-to-contribute of all active agents, their own contribution (in case the subject was an active agent), the total amount of contributions, whether they won the prize, and their entire payoff. In order to make sure that subjects took notice of this feedback, they were asked to record part of it on paper. The payoff at the end of each session was determined by a random selection of one of the twenty rounds.

In the experiment, the marginal per capita return was chosen in such a way that all active agents donating their entire budget was socially optimal when we take into account the payoffs of both the active and the passive agents. Each token donated to the public good generated a return of 1.2 tokens for the group of four. For the sub-society of the active bidders, however, the benefit of providing the public good did not cover the cost. ${ }^{6}$ Exploring this scenario is of particular interest because in reality the donors are often only a subset of the beneficiaries of the public good. Even more importantly, in this scenario the free-riding problem cannot be resolved without prize-based mechanisms or, more generally, mechanisms that transfer some value to the donors. These types of mechanisms are the particular focus of our analysis.

Table 1 presents the expected individual willingness-to-contribute, individual actual contribution, total group contribution, as well as the likelihood that the group contribution is positive and the likelihood that the group contribution exceeds the value of the prize in the (symmetric) equilibrium of the various treatments. ${ }^{7}$ The supplementary material (Appendix A) contains graphs of the cumulative distributions over the individual willingness-to-

\footnotetext{
${ }^{6}$ With $\alpha=0.3$ the total return of 1 token invested in the public good was 0.6 of a token in the case of $n=2$ active players and 0.9 of a token in the case of $n=3$ active players.

${ }^{7}$ We solved all games - in its discretized version as implemented in the experiment, but on a two times rougher grid - using the QRE-solver of Gambit (see http://www.gambit-project.org) that solves for the limiting logit equilibrium as introduced by McKelvey and Palfrey (1995).
} 
contribute, individual actual contribution, and actual group contribution in the symmetric equilibrium.

\begin{tabular}{llrrrrr}
\hline \multirow{2}{*}{ Mechanism } & Number of & \multicolumn{2}{c}{ Ind. contr. } & \multicolumn{3}{c}{ Group contr. } \\
bidders & Will. & Act. & Act. & $>0$ & $\geq V$ \\
\hline \multirow{2}{*}{ OWN-LOT } & $n=2$ & 0.00 & 0.00 & 0.00 & $0 \%$ & $0 \%$ \\
& $n=3$ & 0.00 & 0.00 & 0.00 & $0 \%$ & $0 \%$ \\
OWN-AUC & $n=2$ & 8.00 & 8.00 & 16.00 & $100 \%$ & $0 \%$ \\
& $n=3$ & 6.00 & 6.00 & 18.00 & $100 \%$ & $0 \%$ \\
LOW-VCM & $n=2$ & 14.00 & 14.00 & 28.00 & $100 \%$ & $78 \%$ \\
& $n=2$ & 9.12 & 9.12 & 27.37 & $99 \%$ & $69 \%$ \\
LOW-LOT & $n=3$ & 0.00 & 0.00 & 0.00 & $0 \%$ & $0 \%$ \\
& $n=2$ & 33.62 & 19.93 & 39.87 & $100 \%$ & $100 \%$ \\
LOW-AUC & $n=3$ & 85.04 & 64.50 & 193.50 & $100 \%$ & $100 \%$ \\
& $n=2$ & 43.54 & 24.03 & 48.06 & $92 \%$ & $67 \%$ \\
& $n=3$ & 87.21 & 66.31 & 198.94 & $80 \%$ & $66 \%$ \\
\hline
\end{tabular}

Table 1: Equilibrium predictions.

The numbers in the table reveal some important treatment differences in addition to the optimality of the lowest-bid all-pay auction. First, the mechanisms that entail competition for the prize (via either all-pay auctions or lotteries) generate larger total donations compared to the random assignment of the prize. Second, comparing the all-pay auction with the lottery, we find that the auction is more effective in generating donations. Third, the lowest-bid payment rule generates more revenue than the own-bid payment rule for the lottery and the all-pay auction. Finally, the revenue is increasing in the number of active agents in the lowest-bid lottery and the lowest-bid all-pay auction but stays rather constant in all remaining mechanisms. ${ }^{8}$

\subsection{Results and insights}

Our experiment generated 100 observations of the total group contributions for each treatment (five groups over 20 rounds). As these observations are not independent, and in the treatments with the lowest-bid payment rule the realized group contributions are highly dependent on the actual matching, ${ }^{9}$ we do not perform statistical tests and present summary statistics only. ${ }^{10}$ For the willingness-to-contribute and actual contributions on individual level we have 200 observations for the treatments with 2 active agents and 300 observations for the treatments with 3 active agents.

\footnotetext{
${ }^{8}$ Notice that for the continuous bidding domain the revenue is independent of the number of bidders for the own-bid lottery and the own-bid all-pay auction (see Appendix B). The small differences indicated in the table are due to the discretization and possibly the accumulation of small rounding errors.

${ }^{9}$ We gave feedback on all individual willingness-to-contribute in order to give subjects the opportunity to learn by experience.

${ }^{10}$ The main purpose of this experiment is to test the main result: the theoretical optimality of the lowest-bid all-pay auction mechanism. Therefore, we decided to include many competing mechanism. This came at the expense of the number of (independent) observations per mechanism. We realize that the results and insights we derive should be taken with care.
} 
Table 2 presents the individual willingness-to-contribute, individual actual contributions, and group contributions for the various treatments. We further included the frequency with which group contributions are positive and the frequency with which contributions exceed the prize. For further details on the contributions, we refer to the supplementary material (Appendix A) that contains graphs of the cumulative distributions.

\begin{tabular}{llrrrrr}
\hline \multirow{2}{*}{ Mechanism } & Number of & \multicolumn{2}{c}{ Ind. contr. } & \multicolumn{3}{c}{ Group contr. } \\
& bidders & Will. & Act. & Act. & $>0$ & $\geq V$ \\
\hline OWN-VCM & $n=2$ & 42.15 & 42.15 & 84.30 & $100 \%$ & $97 \%$ \\
& $n=3$ & 33.23 & 33.23 & 99.70 & $100 \%$ & $96 \%$ \\
OWN-LOT & $n=2$ & 49.52 & 49.52 & 99.04 & $100 \%$ & $93 \%$ \\
& $n=3$ & 34.51 & 34.51 & 103.53 & $100 \%$ & $99 \%$ \\
OWN-AUC & $n=2$ & 59.34 & 59.34 & 118.68 & $100 \%$ & $93 \%$ \\
& $n=3$ & 30.29 & 30.29 & 90.86 & $100 \%$ & $90 \%$ \\
LOW-VCM & $n=2$ & 46.71 & 31.34 & 62.68 & $94 \%$ & $89 \%$ \\
LOW-LOT & $n=3$ & 49.79 & 21.12 & 63.36 & $90 \%$ & $65 \%$ \\
& $n=2$ & 73.26 & 57.92 & 115.84 & $95 \%$ & $92 \%$ \\
LOW-AUC & $n=3$ & 72.81 & 42.54 & 127.62 & $68 \%$ & $63 \%$ \\
& $n=2$ & 59.14 & 39.76 & 79.52 & $85 \%$ & $65 \%$ \\
& $n=3$ & 78.30 & 51.15 & 153.45 & $82 \%$ & $72 \%$ \\
\hline
\end{tabular}

Table 2: Experimental outcomes.

Compared to the voluntary contribution mechanism, for both payment rules, a lottery has a positive effect on total donations generated. For the own-bid payment rule, the auction is able to outperform the voluntary contribution mechanism and the lottery only when the number of active agents is low $(n=2)$. When there are more competitors for the prize $(n=3)$, participants seem to duck out of the auction contest - a behavior resulting in auctions being counterproductive. Contributions in the auction are lower compared to the situation in which players are driven by purely intrinsic motivations to donate. For the lowestbid payment rule, the auction outperforms the voluntary contribution mechanism, but the comparison to the lottery, again, depends on the number of competitors. When there are only two active agents, the lottery outperforms the auction, while with three active agents the ranking of these mechanisms is reversed.

In spite of the increase in individual willingness-to-contribute, the introduction of the lowest-bid payment rule has a negative effect on individual actual donations in the voluntary contribution mechanism. In contrast, in the lottery, the increase in individual willingness-tocontribute is sufficient to offset the reduction in total donations associated with the lowest-bid payment rule. The lowest-bid payment rule raises more funds in the lottery compared to the own-bid payment rule. For the auction, however, the effect of introducing the lowestbid payment rule depends on the number of competing donors. With two active bidders, the lowest-bid payment rule has no effect on the individual willingness-to-contribute, and consequently a negative effect on total donations; with three active bidders, a clear gain can be observed. It seems that, in order for the lowest-bid payment rule to be effective in an auction setting, sufficient competition is needed. For two active bidders, there is no difference 
in the individual willingness-to-contribute between the own-bid and the lowest-bid payment rule. Only when there are three active bidders, participants seem to gain a sufficient trust in the functioning of the lowest-bid payment rule (or, lowest order statistics in general), which triggers high donations (and this argument seems to be confirmed by the likelihood for non-zero donations).

In all mechanisms with the own-bid payment rule, the availability of more active agents leads to lower donations on individual level. ${ }^{11}$ For the voluntary contribution mechanism this may be due to a decrease in perceived responsibility for the community; for the lottery and the auction there is the additional effect related to the lower chance for winning the prize. In the mechanisms with the lowest-bid payment rule, in contrast, the individual willingnessto-contribute does not decline when the number of active agents increases. For the voluntary contribution mechanism and the lottery, the individual actual contribution decreases in the number of active agents, while for the auction it increases.

Overall, we find that the theoretical optimality of the lowest-bid all-pay auction is experimentally validated only when the number of competing donors is large enough to establish sufficient trust in the functioning of the lowest order statistic that is inherent to the lowest-bid payment rule.

\section{Conclusion}

In an effort to bring budget deficits under control without raising taxes, communities increasingly rely on the non-profit sector to provide a variety of public goods and services which have traditionally been provided by governments. For instance, in her proposed budget for the fiscal years 2011-2013, the state of Washington governor Gregoire announced that "[...] the safety net will be stretched thin in some places and eliminated entirely in others." Cuts in basic services such as, for instance, education and health-care are on the agenda in virtually every state across the US. It is well-known that voluntary contribution mechanisms for the private provision of public goods are not be able to produce efficient outcomes because of free-riding incentives. In the past several decades economists have responded to the free-rider problem by studying, both theoretically and experimentally, various schemes for the private provision of public goods ranging from point provision mechanisms to matching and rebate schemes, to seed money and refunds. One commonly used but increasingly important source of revenue is the use of prize-based mechanisms, e.g. auctions and lotteries, for charitable fund-raising.

This paper derives the optimal fund-raising mechanism in a simple model in which a prize of commonly known value is awarded to one of the donors. Theoretically, the lowest-price all-pay auction is the optimal mechanism. Yet, this result is behaviorally fragile. We find

\footnotetext{
${ }^{11}$ This result is consistent with the general conclusion from the experimental literature regarding the effect of the number of players on individual behavior in contests (see Dechenaux et al., 2012).
} 
that the lowest-price all-pay auction generates the highest revenue only if there is a sufficient number of active bidders.

Our analysis opens various opportunities for further theoretical and experimental research. An assumption which is probably most often violated in reality is the symmetry of the bidders. In this paper, we assume symmetry across three important dimensions: budgets, individual benefit from the public good, and equilibrium behavior. Relaxing any of these symmetry assumptions, albeit theoretically challenging, can generate new insights. Recent work by Bos (2011) shows that the dominance of the own-bid all-pay auction over the lottery does not generally hold if bidders vary in the way they value the prize and the public good if this asymmetry is sufficiently strong. How to design optimal mechanisms when such asymmetries are present is largely unknown.

Another important extension is to allow for endogenous participation by donors. In a field experiment, Carpenter et al. (2008) observe that, in contrast to theory, the winner-pay first-price auction generates more revenue than the own-bid all-pay auction (and the winnerpay second price auction) - a finding that the authors attribute to endogenous participation. In a more recent theoretical work, Carpenter, Holmes and Matthews (2010) derive the symmetric Bayes-Nash equilibria in the above three mechanisms in a setting in which bidder have mechanism-specific entry costs and decide whether they wish to participate or not. The design of optimal fund-raising mechanisms with endogenous participation, however, is still unexplored even in symmetric settings.

Finally, our model considers the fund-raising activity in isolation of future fund-raisers. Many fund-raising efforts, are, however, repeated events in which behavioral spill-overs play a role. Using a field experiment, Landry, Lange, List, Price and Rupp (2010) find that previous donors are more likely to give than those who are asked for a first time to contribute, and explore the factors that keep donors committed to the cause. One important conclusion that Landry et al. (2010) draw is that donors initially attracted via economic mechanisms such as auctions, lotteries, seed money, matching grants, etc. - are more likely to continue to contribute in the future than the ones attracted by "non-mechanism" factors (e.g. the appearance of the solicitor). Thus, theoretical and experimental work on optimal economic mechanisms for fund-raising that explicitly accounts for the recurrence of fund-raising events presents an important avenue for future research. 


\section{References}

1. Andreoni J (1998). Toward a theory of charitable fund-raising. Journal of Political Economy 106(6): 1186-1213.

2. Bagnoli M and BL Lipman (1989). Provision of public goods: Fully implementing the core through private contributions. Review of Economic Studies 56(4): 583-601.

3. Bagnoli M and M McKee (1991). Voluntary contribution games: Efficient private provision of public goods. Economic Inquiry 29(2): 351-366.

4. Baye MR, D Kovenock and CG de Vries (1996). The all-pay auction with complete information. Economic Theory 8(2): 291-305.

5. Blume A and P Heidhues (2004). All equilibria of the Vickrey auction. Journal of Economic Theory 114(1): 170-177.

6. Bos O (2011). How lotteries outperform auctions. Economic Letters 110(3): 262-264.

7. Carpenter J, J Holmes and PH Matthews (2008). Charity auctions: A field experiment. Economic Journal 118(525): 92-113.

8. Carpenter J, J Holmes and PH Matthews (2010). Endogenous participation in charity auctions. Journal of Public Economics 94(11-12): 921-935.

9. Che Y-K and IL Gale (1998). Caps on political lobbying. American Economic Review 88(3): 643-651.

10. Clarke EH (1971). Multipart pricing of public goods. Public Choice 11: 17-33.

11. Corazzini L, M Faravelli and L Stanca (2010). A prize to give for: An experiment on public good funding mechanisms. Economic Journal 120(547): 944-967.

12. Dechenaux E, D Kovenock and RM Sheremeta (2012). A survey of experimental research on contests, all-pay auctions and tournaments. Working paper.

13. Duffy J and A Matros (2012). All-pay auctions vs. lotteries as provisional fixed-prize fundraising mechanisms: Theory and Evidence. Working paper, University of Pittsburgh.

14. Fischbacher U (2007). zTree: Zurich toolbox for ready-made economic experiments. Experimental Economics 10(2): 171-178.

15. Goeree JK, E Maasland, S Onderstal and JL Turner (2005). How (not) to raise money. Journal of Political Economy 113(4): 897-918.

16. Govindan S, PJ Reny and AJ Robson (2003). A short proof of Harsanyi's purification theorem. Games and Economic Behavior 45(2): 369-374. 
17. Groves T (1973). Incentives in teams. Econometrica 41(4): 617-631.

18. Groves T and J Ledyard (1977). Optimal allocation of public goods: A solution to the "free rider" problem. Econometrica 45(4): 783-809.

19. Harsanyi JC (1973). Games with randomly disturbed payoffs: A new rationale for mixed-strategy equilibrium points. International Journal of Game Theory 2: 1-23.

20. Hillman AL and D Samet (1987). Dissipation of contestable rents by small numbers of contenders. Public Choice 54(1): 63-82.

21. Konrad KA (2009). Strategy and Dynamics in Contests. Oxford University Press.

22. Landry CE, A Lange, JA List, MK Price and NG Rupp (2006). Toward an understanding of the economics of charity: Evidence from a field experiment. Quarterly Journal of Economics 121(2): 747-782.

23. Landry CE, A Lange, JA List, MK Price and NG Rupp (2010). Is a donor in hand better than two in the bush? Evidence from a natural experiment. American Economic Review 100(3): 958-983.

24. Lange A, JA List and MK Price (2007). Using lotteries to finance public goods: Theory and experimental evidence. International Economic Review 48(3): 901-927.

25. McKelvey RD and TR Palfrey (1995). Quantal response equilibria for normal form games. Games and Economic Behavior 10(1): 638.

26. Morgan J (2000). Financing public goods by means of lotteries. Review of Economic Studies 67(4): 761-785.

27. Morgan J and M Sefton (2000). Funding public goods with lotteries: An experiment. Review of Economic Studies 67(4): 785-810.

28. Onderstal S, AJHC Schram and AR Soetevent (2011). Bidding to give in the field: Door-to-door fundraisers had it right from the start. Tinbergen Institute working paper \#11-070/1.

29. Orzen H (2008). Fundraising through competition: Evidence from the lab. CeDEx Discussion Paper No. 200811, University of Nottingham.

30. Schram AJHC and S Onderstal (2009). Bidding to give: An experimental comparison of auctions for charity. International Economic Review 50(2): 431-457.

31. Walker M (1981). A simple incentive compatible scheme for attaining Lindahl allocations. Econometrica 49(1): 65-71. 


\section{Appendix A Theoretical and experimental outcomes}

\section{A.1 Individual willingness-to-contribute}

Own-bid

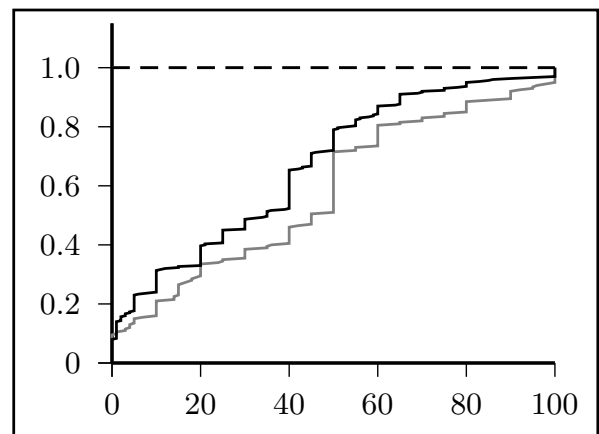

Lottery

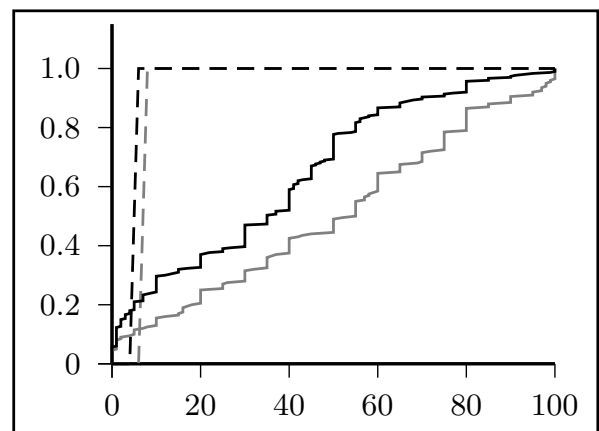

Auction

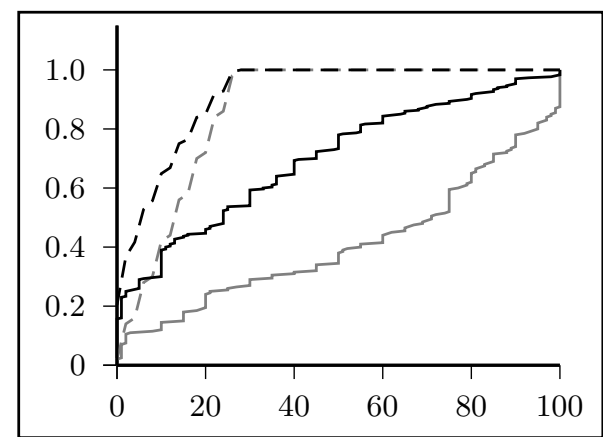

Lowest-bid
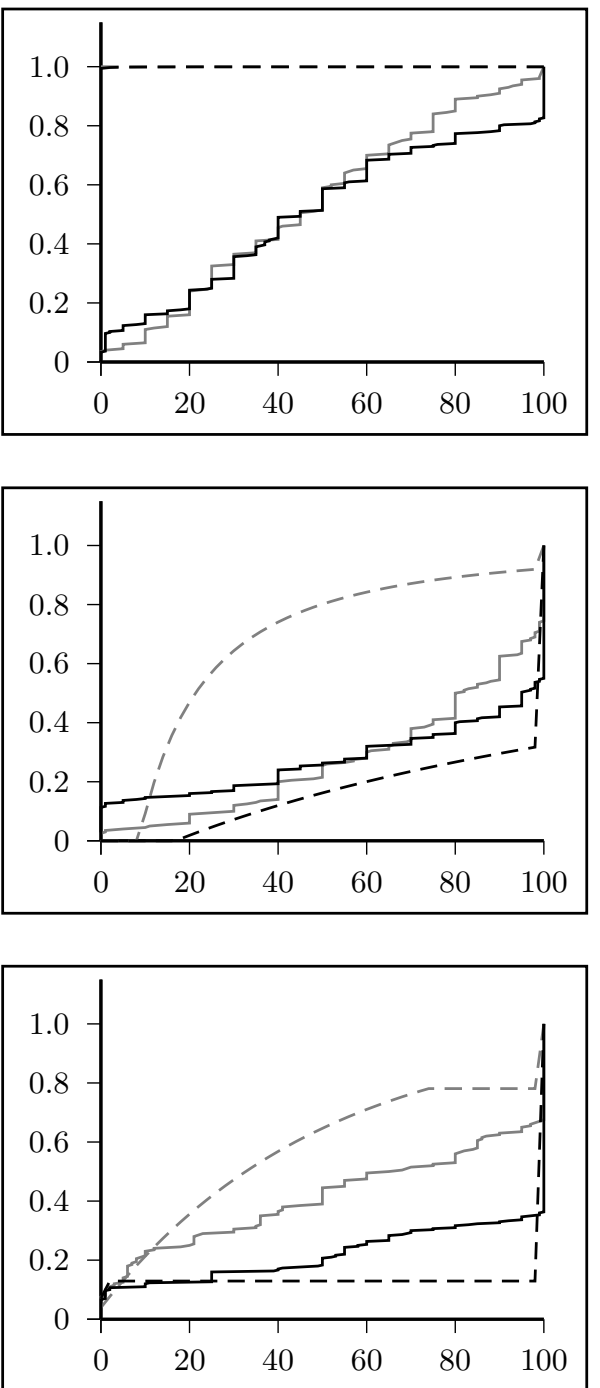

Figure 1: The figures provide the cumulative distribution over all individual decisions. Dashed lines refer to theoretical prediction; solid lines to experimental outcomes. Gray lines refer to two active agents; black lines to three active agents. 


\section{A.2 Individual actual contribution}

Own-bid

VCM

Lottery

Auction
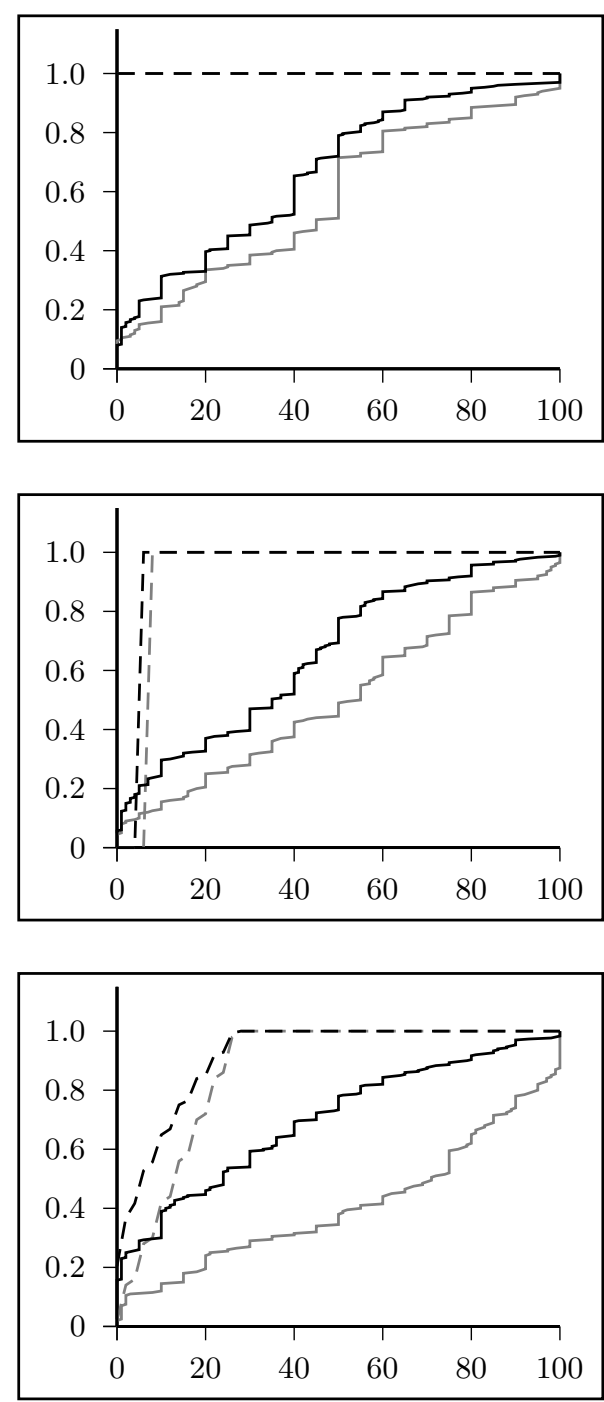

Lowest-bid
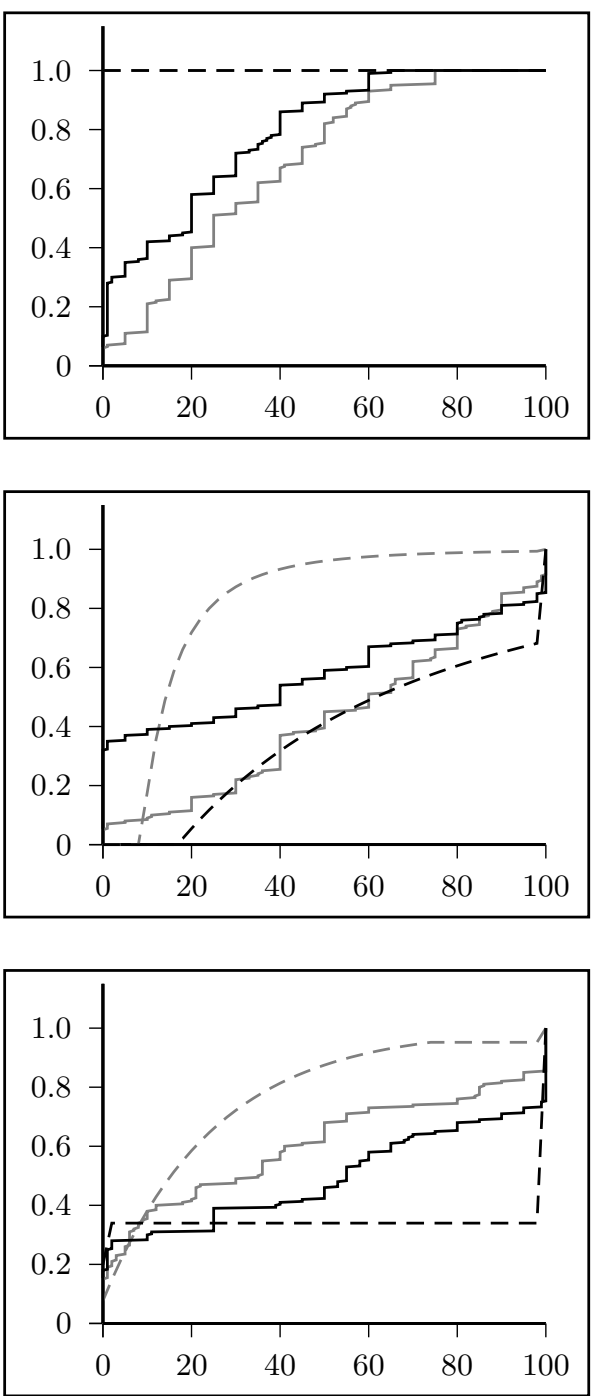

Figure 2: The figures provide the cumulative distribution over all individual actual contribution levels. Dashed lines refer to theoretical prediction; solid lines to experimental outcomes. Gray lines refer to two active agents; black lines to three active agents. 


\section{A.3 Group contribution}

Own-bid
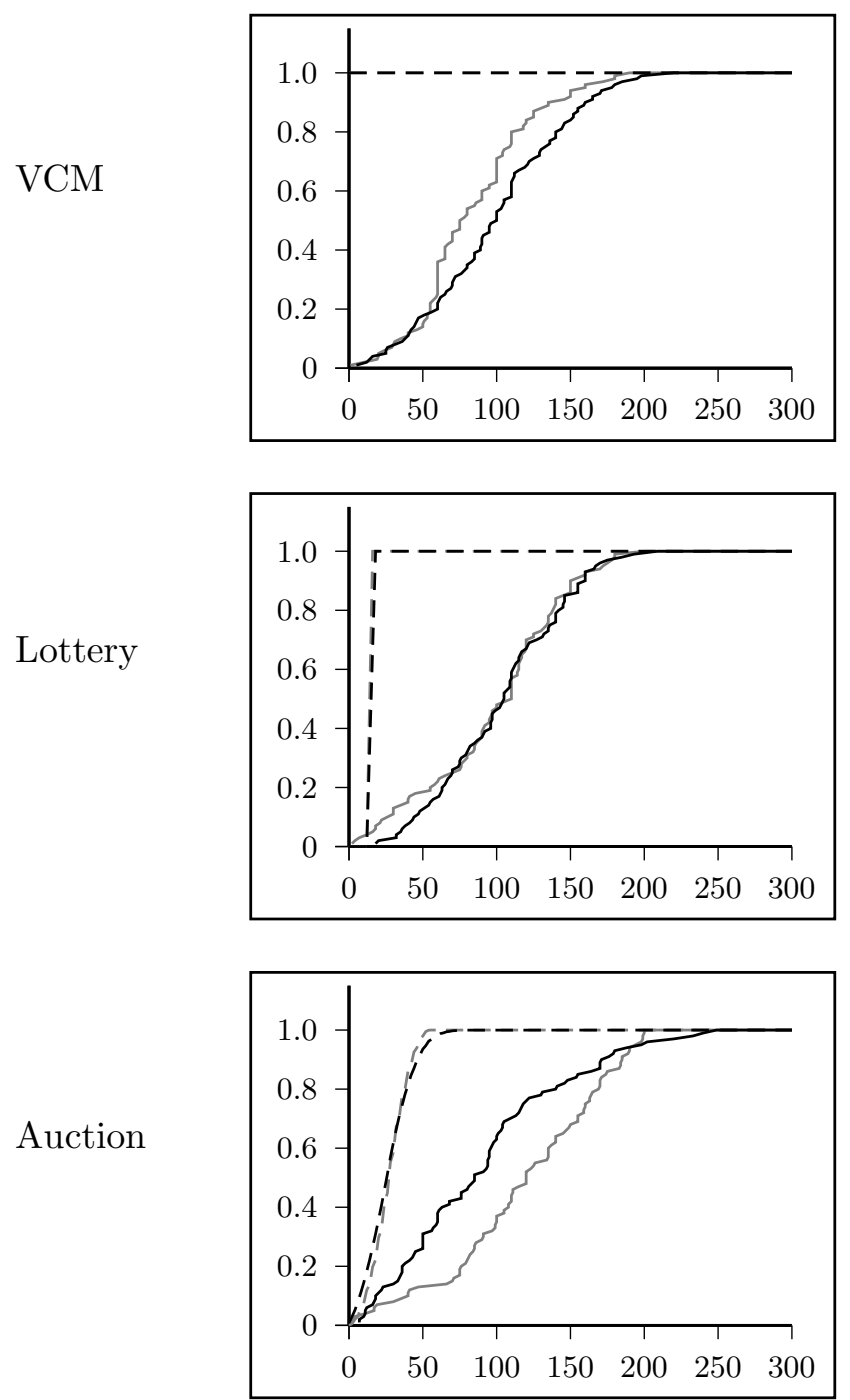

Lowest-bid
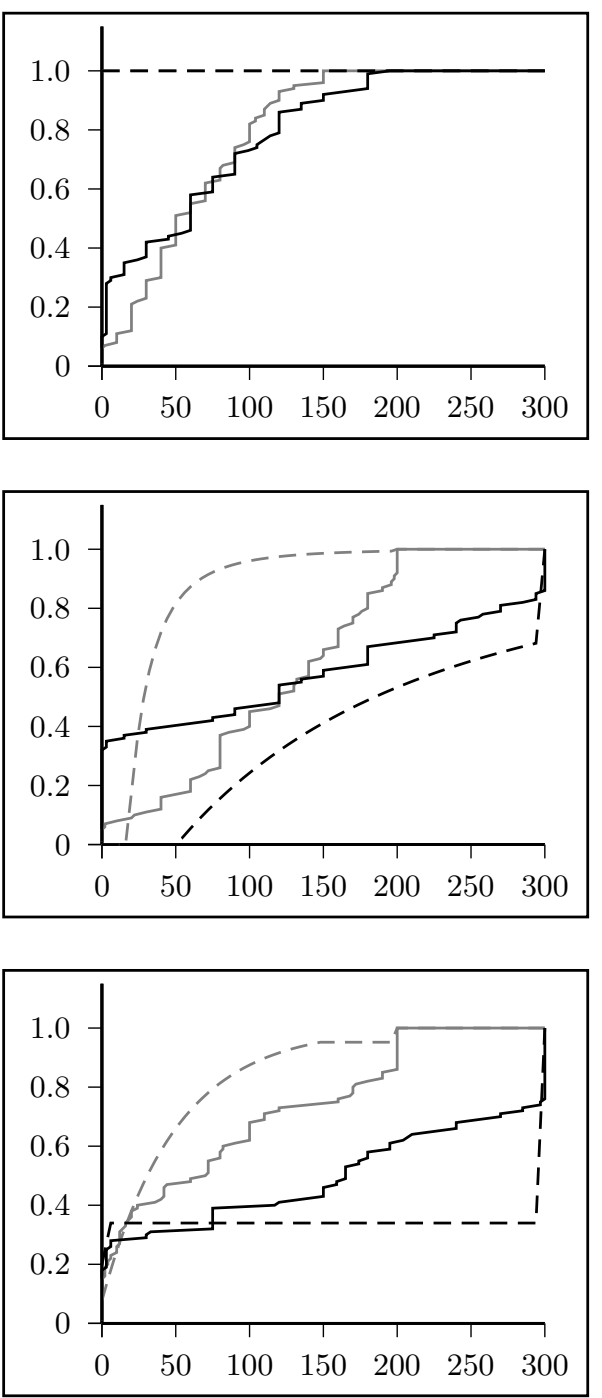

Figure 3: The figures provide the cumulative distribution over all group contribution levels. Dashed lines refer to theoretical prediction; solid lines to experimental outcomes. Gray lines refer to two active bidders; black lines to three active bidders. 


\section{Appendix B The own-bid all-pay auction}

In this appendix we analyze the own-bid all-pay auction. From Lemma 1 it follows that this auction has the same equilibria as an auction with a marginal per capita return of zero $(\alpha=0)$ in which a prize of size $\frac{V}{1-\alpha}$ is awarded to the winner. ${ }^{12}$ This observation allows us to use some results from the theoretical literature on the all-pay auction with complete information (Baye, Kovenock and de Vries, 1996) and from the literature on caps on political lobbying (Che and Gale, 1998). As we will show, most of these results can be applied (with minor modifications) in the current setting, which permits us to characterize the set of all equilibria. In the case of two bidders there is a unique equilibrium given in symmetric mixed strategies. In the case of three or more bidders, we show that there is a unique symmetric (mixed strategy) equilibrium, and a continuum of asymmetric equilibria. In all equilibria, however, expected revenue is the same, does not depend on the number of bidders, and equals $\frac{V}{1-\alpha}$ given that the budget constraint $B$ is not so small that all players prefer to donate their entire budget in equilibrium. The next proposition summarizes the equilibria of the own-bid all-pay auction depending on the budget constraint $B$.

Proposition 6 (Equilibrium strategies).

(a) Non-binding budget constraint: $B \geq \frac{V}{1-\alpha}$. There are no Nash equilibria in pure strategies. In the case of two bidders there is a unique Nash equilibrium in mixed strategies. In this equilibrium bidders randomize on the interval $\left[0, \frac{V}{1-\alpha}\right]$ according to the cumulative distribution function

$$
F(x)=\left(\frac{1-\alpha}{V} \cdot x\right)^{\frac{1}{n-1}} .
$$

In the case of three or more bidders there is a unique symmetric Nash equilibrium with the c.d.f. $F(x)$ and a continuum of asymmetric equilibria. In the asymmetric equilibria some of the bidders do not contribute with a positive probability.

(b) Binding budget constraint: $\frac{V}{n(1-\alpha)} \leq B<\frac{V}{1-\alpha}$. There are no Nash equilibria in pure strategies. In the case of two bidders there is a unique Nash equilibrium. In this equilibrium bidders randomize on the interval $\left[0,2 B-\frac{V}{1-\alpha}\right]$ according to $F(x)$ and contribute their entire budget with a probability of $2\left(1-(1-\alpha) \frac{B}{V}\right)$.

In the case of three or more bidders there is a unique symmetric Nash equilibrium and a continuum of asymmetric equilibria. In the symmetric equilibrium bidders randomize on the interval $[0, b]$ according to $F(x)$ and donate their entire budget with a probability of $1-F(b)$. The cutoff value $b$ is determined by the unique solution to the equation

$$
\frac{V}{1-\alpha} \cdot\left[\frac{1-F(b)^{n}}{n(1-F(b))}\right]=B
$$

\footnotetext{
${ }^{12}$ This property applies because the payoffs an the auction with a prize of $\frac{V}{1-\alpha}$ are a linear transformation of the payoffs of the public good setting we consider. Such a linear transformation of the payoffs leaves the best response correspondences unaltered, and, hence, has no effect on the set of equilibria.
} 
In the asymmetric equilibria some of the bidders do not donate with a positive probability.

(c) Low budget constraint: $B<\frac{V}{n(1-\alpha)}$. There is a unique Nash equilibrium in which all participants contribute their entire budget $B$. The payoff of each participant is $\frac{V}{n}+$ $(\alpha n-1) B$.

Proof. Lemma 1 allows us to focus on the own-bid all-pay auction with a prize of $\frac{V}{1-\alpha}$. The uniqueness of equilibrium and the equilibrium distribution with a budget constraint in the case of two bidders is derived in Che and Gale (1998, Lemma 3 and Proposition 1). The general case of $n$ bidders with no budget constraint can be found in Baye et al. (1996). Here we will discuss the equilibria with a binding budget constraint of $B \leq \frac{V}{1-\alpha}$. The proof is organized as follows. We first show that the distribution function stated in the proposition indeed forms a symmetric equilibrium. Then we argue than no other symmetric equilibria exist. Finally, we discuss asymmetric equilibria.

Step 1. The stated distribution function forms a symmetric equilibrium. Observe that, when all other bidders play the stated mixed strategies, the payoff of bidder $i$ with any bid $x_{i} \in[0, b]$ equal $F\left(x_{i}\right)^{n-1} \cdot \frac{V}{1-\alpha}-x_{i}=0$. Now we will show that, when $b$ satisfies the equation stated in Part (b) of the proposition, the payoff of a player with a bid $B$ is also zero. The bids $b$ and $B$ generate the same payoff if and only if the additional expected gain from increasing the bid from $b$ to $B$ equals the additional cost. As already discussed (see Step 6 in the proof of Proposition 1), by raising his bid from $b$ to $B$, a bidder increases his probability of winning the prize by

$$
\frac{1-F(b)^{n}}{n(1-F(b))}-F(b)^{n-1}
$$

and the additional cost incurred by this bidder equals $(B-b)$. Hence, the payoff of a bidder with the bid of $B$ will be zero if and only if for the cutoff value $b$ holds

$$
\frac{V}{1-\alpha} \cdot\left[\frac{1-F(b)^{n}}{n(1-F(b))}-F(b)^{n-1}\right]=(B-b) .
$$

Using that $F(b)=\left(\frac{1-\alpha}{V} \cdot x\right)^{\frac{1}{n-1}}$, we can rewrite the above equation as

$$
\frac{V}{1-\alpha} \cdot\left[\frac{1-\left(\frac{1-\alpha}{V} \cdot x\right)^{\frac{n}{n-1}}}{n\left(1-\left(\frac{1-\alpha}{V} \cdot x\right)^{\frac{1}{n-1}}\right)}-\frac{V}{1-\alpha} \cdot b\right]=(B-b) \Longleftrightarrow \frac{V}{1-\alpha} \cdot\left[\frac{1-F(b)^{n}}{n(1-F(b))}\right]=B .
$$

This equation has a unique solution because, as can easily be established, the left hand-side is monotonically increasing in $b$. To see this note that

$$
\frac{1-F(b)^{n}}{(1-F(b))}=\sum_{j=0}^{n-1} F(b)^{j}
$$

As all points in the stated equilibrium distribution yield for bidder $i$ the same payoff of 0 , the stated mixed strategy yields the same payoff. To complete the proof, note that any bid in 
the interval $(b, B)$ leads to a payoff smaller than zero because the winning probability of each bidder is the same as with the strategy $b$, but a bidder has to pay more. Thus, the described strategies are equilibrium strategies.

Step 2. No other symmetric equilibria exist. We first observe that there are no mass points in the equilibrium distribution except possibly at $B$. The existence of mass points in a symmetric mixed strategy equilibrium involves ties at these points. A bidder can marginally shift up a mass point, and this will be a profitable deviation. A tie which occurs with a strictly positive probability will be resolved in the bidder's favor with arbitrary small extra cost (see also Hillman and Samet, 1987, footnote 7, for details). Next, we observe that zero is in the support of the distribution. Assume that the lower bound of the support is $\ell_{i}>0$. As no mass points exist, the probability of winning the prize with this bid is zero, but this bidder pays a positive amount. Playing zero is hence a profitable deviation. Since zero is in the support, the expected payoff of a bidder with each bid in the support, in particular the equilibrium mixed strategy, must equal the expected payoff with a zero bid. Let us assume that the average donation according to the equilibrium mixed strategy is $E$. If all other bidders follow the equilibrium mixed strategy, the expected payoff with the equilibrium mixed strategy equals $\frac{V}{n}+\alpha \cdot n \cdot E$. If a bidder bids zero, the bidder gains only from the donations of the remaining bidders which amount to $\alpha \cdot(n-1) \cdot E$. Solving the equation

$$
\frac{V}{n}+\alpha \cdot n \cdot E=\alpha \cdot(n-1) \cdot E,
$$

we obtain $E=\frac{V}{n(1-\alpha)}$, which is the expected donation in every symmetric mixed strategy equilibrium. The rest of the proof is identical to the uniqueness proof for the lowest-price all-pay auction (see Step 5 in the proof) and is, therefore, omitted here.

Step 3. Asymmetric equilibria. This auction format admits a variety of asymmetric equilibria. One class of asymmetric equilibria involves a number of $m$, where $n>m \geq 2$, bidders being active and playing a symmetric mixed strategy as the one in a game with $m$ bidders only, and the rest of the bidders playing a pure strategy of a zero bid (i.e. not donating). It is straightforward that these strategy profiles are equilibria. Indeed, according to this strategy profile, both the active and the passive players earn an expected payoff of zero. There are no profitable deviations for the active bidders because these deviations would have been profitable in a game with only $m$ bidders. Note also that any positive bid of a passive bidder would lead to a negative expected payoff for that bidder because the gain in probability of winning the item would too small to compensate for the additional cost associated with a positive bid. ${ }^{13}$ This completes Part (a) and Part (b) of the proposition.

We now move to the proof of Part (c). We first verify that the strategy profile in which all bidders donate their entire budget is an equilibrium, and then we demonstrate that no other equilibria exist. When all bidders play $B$, the expected gain from earning the prize is

\footnotetext{
${ }^{13}$ For a complete description of the mixed strategy equilibrium set without a budget constraint, see Baye et al. (1996).
} 
$\frac{V}{n(1-\alpha)}$ which exceeds $B$. Any deviation of a single bidder to a lower amount will result in zero chance of earning the prize and is thus not profitable. Hence, all bidders contributing their entire budget is an equilibrium. We will next show that no other equilibria exist (in mixed or pure strategies).

We first verify that the lower bounds of the mixed strategy probability distribution of all bidders is the same: $\ell_{1}=\ell_{2}=\cdots=\ell_{n}$. Assume, on the contrary that there exists a $i$ such that $\ell_{i}<\max _{j \neq i} \ell_{j}$, and observe that with the bids from the interval $\left[\ell_{i}, \max _{j \neq i} \ell_{j}\right)$ bidder $i$ always loses the contest to one of the other bidders. Then a deviation according which bidder $i$ transfers the mass $\phi_{i}\left[\left(\ell_{i}, \max _{j \neq i} \ell_{j}\right)\right]$ to $B$ is profitable because the additional expected gain from winning the prize is at least $\phi_{i}\left[\ell_{i}, \max _{j \neq i} \ell_{j}\right] \cdot \frac{V}{n(1-\alpha)}$ and the additional expected cost is not higher than $\phi_{i}\left[\left(\ell_{i}, \max _{j \neq i} \ell_{j}\right)\right] \cdot B$.

We now show that there is no mass point at the lower bound: $\phi_{i}\left[\ell_{i}\right]=0$ for all $i$. If there are two or more bidders with a positive mass on the point $\ell_{i}$, each one of them (say bidder i) can improve his expected payoff by shifting the mass $\phi_{i}\left[\ell_{i}\right]$ to the point $\ell_{i}+\epsilon$. In doing so that bidder will for sure win against another player who plays $\ell_{i}$. The expected gain from this deviation is the additional probability of winning multiplied by $\frac{V}{1-\alpha}$. The expected cost is bounded from above by $\epsilon$, and for $\epsilon$ small enough the deviation is profitable. If bidder $i$ is the only bidder with a mass point at $\ell_{i}$, this bidder loses with the bid of $\ell_{i}$ with certainty. Shifting the mass $\phi_{i}\left[\ell_{i}\right]$ to the point $B$ is profitable for this bidder. As we already know that all bidders have the same lower bound $\ell_{i}$, and there is no mass point at that bound, we consider a deviation according to which bidder $i$ shifts the mass $\phi_{i}\left[\left[\ell_{i}, \ell_{i}+\epsilon\right)\right]$ to the point $B$. For each $\delta>0$ we can choose $\epsilon$ small enough so that $\prod_{j \neq i} \phi_{j}\left[\left[\ell_{i}, \ell_{i}+\epsilon\right)\right]<\delta$. Thus, by playing this deviation, bidder $i$ increases his payoff from winning the prize by least $\phi_{i}\left[\left[\ell_{i}, \ell_{i}+\epsilon\right)\right] \cdot\left(\frac{1}{n}-\delta\right) \frac{V}{1-\alpha}$. The additional cost of this deviation is not larger than $\phi_{i}\left[\left[\ell_{i}, \ell_{i}+\epsilon\right)\right] \cdot B$. Thus, $\delta$ can be chosen small enough so that the additional gain exceeds the cost of the deviation.

The own-bid all-pay auction format has three intriguing features. First, despite the multiplicity of equilibria in the case of $n \geq 3$ bidders, as we will establish in the next proposition, the expected revenue in all equilibria is the same. Second, the expected revenue is not affected by the budget constraint $B$ unless $B$ is so low relative to $V$ and $\alpha$ that bidders find it advantageous to contribute their entire budget. Finally, the expected revenue does not depend on the number of participants $n$.

Proposition 7 (Expected revenue). When $B>\frac{V}{n(1-\alpha)}$ all mixed strategy equilibria generate the same expected revenue of $\frac{V}{1-\alpha}$ independent of the number of bidders $n$. When $B \leq \frac{V}{n(1-\alpha)}$ all participants contribute their entire budget $B$ in equilibrium.

Proof. We already established that all equilibrium mixed strategies have the same lower bound at zero and that a person who bids zero has an expected payoff of zero (given that the other players are playing the equilibrium strategy). If there exists a bidder without a mass point at the lower bound, then the winning chances of another bidder who plays the lower 
bound is zero. In this case the lower bound can only be zero, and the payoff of all bidders in equilibrium is zero (otherwise the payoff would be negative, and bidders cannot get negative payoffs in equilibrium as otherwise they would bid zero). If all bidders have a mass point at the lower bound, then each bidder has an incentive to marginally increase the position of this mass point to avoid the tie with the other bidders. Thus, the only possibility is that the lower bound is zero and all bidders earn an expected payoff of zero at the lower bound. This shows that for all bidders the expected payoff in equilibrium is zero as this is the payoff of any strategy in the support. As the prize is assigned with a probability of one, for all bidders to have an expected payoff of zero it must be the case that the sum of the expected donations of all bidders equals $\frac{V}{1-\alpha}$. 